\title{
Application of STATCOM to increase transient stability of wind farm
}

\author{
Bouhadouza Boubekeur, Ahmed Gherbi, Hacene Mellah \\ Department of Electrical Engineering, Sétif-1 University, Algeria \\ Email address: \\ bouhadouza_b@yahoo.fr (B. Bouhadouza),gherbi_a@yahoo.fr (A. Gherbi), has.mel@gmail.com (H. Mellah)
}

\section{To cite this article:}

Bouhadouza Boubekeur, Ahmed Gherbi, Hacene Mellah. Application of STATCOM to Increase Transient Stability of Wind Farm, American Journal of Electrical Power and Energy Systems. Vol. 2, No. 2, 2013, pp. 50-56. doi: 10.11648/j.epes.20130202.14

\begin{abstract}
In this paper we interested to the study the necessary of Facts to increase the transient stability on the presence of faults and the integration of new renewable source, like wind energy, these lasts make the electrical grid operate in a new conditions, the STATCOM is one of the important Facts element, It provides the desired reactive-power generation and absorption entirely by means of electronic processing of the voltage and current waveforms in a voltage source converter (VSC). This function is identical to the synchronous condenser with rotating mass. In present work we propose a transient stability improvement using STATCOM under faults, in the first time we study the transient stability with and without STATCOM for clearly his advantages. In the second time we know the relation between the reactive power injecting by a STATCOM and the critical clearing time, some simulation results are given, commented and discussed.
\end{abstract}

Keywords: Transient Stability, Reactive Power, FACTS, STATCOM, Wind Power, CCT

\section{Introduction}

There is now general acceptance that the burning of fossil fuels is having a significant influence on the global climate. Effective mitigation of climate change will require deep reductions in greenhouse gas emissions, with UK estimates of a $60-80 \%$ cut being necessary by 2050 [1], Still purer with the nuclear power, this last leaves behind dangerous wastes for thousands of years and risks contamination of land, air, and water; the catastrophe of Japan is not far[2], to avoid the problems of the pollution, the energy policy decision states that the objective is to facilitate a change to an ecologically sustainable energy production system such as wind power [3], but the major problem is how associate the wind power stations to the grid with assure the linking conditions[4]. In addition, now a day's power transmission and distribution systems face increasing demands for more power, better quality and higher reliability at lower cost, as well as low environmental effect Under these conditions, transmission networks are called upon to operate at high transmission levels, and thus power engineers have had to confront some major operating problems such as transient stability, damping of oscillations and voltage regulation etc [5], in this work we interest to the transient stability, this last indicates the capability of the power system to maintain synchronism when subjected to a severe transient disturbances such as fault on heavily loaded lines, loss of a large load etc [6].Generator excitation controller with only excitation control can improve transient stability for minor faults but it is not sufficient to maintain stability of system for large faults occur near to generator terminals [6]. Researchers worked on other solution and found that flexible AC transmission systems (FACTS) are one of the most prominent solution [7], [8].

The objective principal to use FACTS technology for the operators of the electric power is to have an opportunity for the control of the power flow and by increasing the capacities usable of these lines under the normal conditions. The parameter which controls the operation of transmission of energy in a line such as the impedances series and shunts, running, tension and phase angle is controlled by utilizing FACTS controllers. FACTS devices increases power handling capacity of the line and improve transient stability as well as damping performance of the power system [7], [8].

According to the specialized literature we find several types of FACTS [6-11], in our work we are limited to the study a great disturbance, so the FACTS element used for reactive power compensation both assuring the low cost and high efficiency is STATCOM.

The static synchronous compensators (STATCOM) consist of shunt connected voltage source converter through coupling transformer with the transmission line. STAT- 
COM can control voltage magnitude and, to a small extent, the phase angle in a very short time and therefore, has ability to improve the system [7], [8].

\section{Wind Turbine Model}

\subsection{Squirrel Cage Induction Generator}

The fixed speed wind generator systems have been used with a multiple-stage gearbox and a SCIG directly connected to the grid through a transformer [11].

The well-known advantages of SCIG are it is robust, easy and relatively cheap for mass production [11], electrically fairly simple devices consisting of an aerodynamic rotor driving a low-speed shaft, a gearbox, a high-speed shaft and an induction generator [12].

The gearbox is needed, because the optimal rotor and generator speed ranges are different, we find also a polechangeable SCIG has been used in some commercial wind turbines; it does not provide continuous speed variations [11]. The generator is directly grid coupled. Therefore, rotor speed variations are very small, because the only speed variations that can occur are changes in the rotor slip[13], because the operating slip variation is generally less than $1 \%$, this type of wind generation is normally referred to as fixed speed [12].

A SCIG consumes reactive power. Therefore, in case of large wind turbines and/or weak grids, often capacitors are added to generate the induction generator magnetizing current, thus improving the power factor of the system as a whole [13].

The power extracted from the wind needs to be limited, because otherwise the generator could be overloaded or the pullout torque could be exceeded, leading to rotor speed instability. In this concept, this is often done by using the stall effect. This means that the rotor geometry is designed in such a way that its aerodynamic properties make the rotor efficiency decrease in high wind speeds, thus limiting the power extracted from the wind and preventing the generator from being damaged and the rotor speed from becoming unstable [13], so the operating condition of a squirrelcage induction generator, used in fixed-speed turbines, is dictated by the mechanical input power and the voltage at the generator terminals. This type of generator cannot control bus bar voltages by itself controlling the reactive power exchange with the network. Additional reactive power compensation equipment, often fixed shunt-connected capacitors, is normally fitted [12]; this system concept is also known as the 'Danish concept' and is depicted in Fig 1 [13].

The slip is generally considered positive in the motor operation mode and negative in the generator mode. In both operation modes, higher rotor slips result in higher current in the rotor and higher electromechanical power conversion. If the machine is operated at slips greater than unity by turning it backwards, it absorbs power without delivering anything out i.e. it works as a brake. The power in this case is converted into $I$ heat loss in the rotor conductor that needs to be dissipated [14].

Fig. 1 shows the torque-slip characteristic of the induction machine in the generating mode. If the generator is loaded at constant load torque $T_{L}$ only $P 1$ is stable. The loading limit of the generator i.e. the maximum torque it can support is called the breakdown torque and represented in the Fig. 1 as $T_{\max }$ If the generator is loaded under a constant torque above $T_{\max }$, it will become unstable and stall, draw excessive current and destroy itself thermally if not properly protected [14].

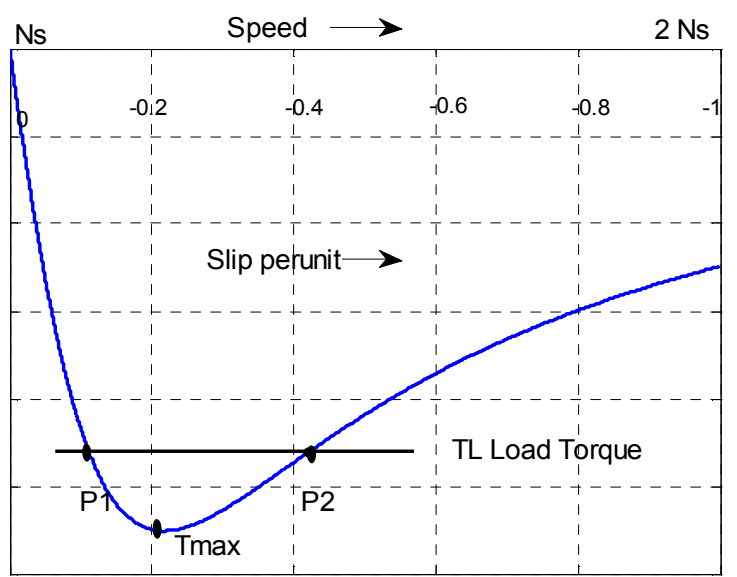

Figure 1. Torque versus slip characteristic of an induction generator [14].

\subsection{Modeling for Fixed - Speed Wind Turbines}

The modeling of wind turbine plays an important role in the building of stability concept. Every research recently uses grid model, wind turbine model and wind speed model as a foundation. The specific simulation approach used to study the dynamics of large power systems is reduced-order modeling of wind turbine. This model uses several assumptions and gives the models the various subsystems of each of the recent wind turbine types as presents at the Fig.2 [14].

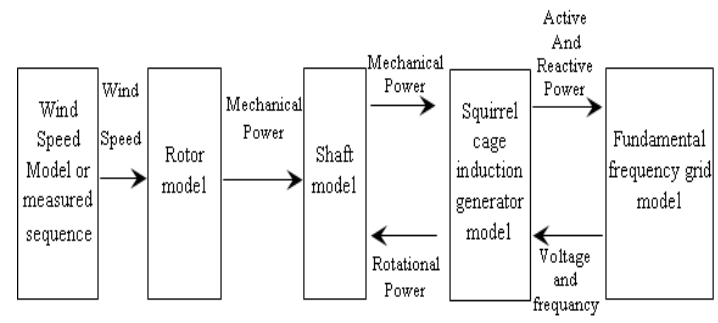

Figure 2. Generator structure of fixed-speed wind turbine model [6].

We use Matlab to modeling the wind turbine system in two main blocks: rotor model and generator model.

\subsubsection{Rotor Model}

The traditional rotor model in wind turbine simulation is base on the well known equation which gives the relationship between the power extracted from wind and wind speed [14]: 


$$
P_{w t}=C_{p} P_{v}=C_{p}(\lambda, \beta) \cdot \frac{\rho A_{w t} v_{w}^{3}}{2}
$$

Where $C_{p}$ is the power coefficient of wind turbine $\left(C_{p}\right.$ is the function of the blade pitch angle $\beta$ and the tip-speed ratio); $\rho$ is the air density; $A_{w t}$ is the swept area; $v$ is the wind speed. The tip-speed ratio $\lambda$.is defined as:

$$
\lambda=\frac{w_{w t} \cdot R}{v}
$$

Where $\mathrm{w}_{\mathrm{wt}}$ is mechanical angular velocity of wind turbine blades; $\mathrm{R}$ is radius of wind turbine blades. The numerical method of $C_{p}$ is in $\operatorname{Ref}[15]$.

$$
C_{p}(\lambda, \beta)=0.5176\left(\frac{116}{\lambda_{\mathrm{i}}}-0.4 \beta-5\right) \mathrm{e}^{\frac{-21}{\lambda_{\mathrm{i}}}}+0.0068 \lambda
$$

Where

$$
\lambda_{i}=\left[\frac{1}{\lambda+0.08 \beta}-\frac{0.035}{\beta^{3}+1}\right]^{-1}
$$

There is always an optimum tip speed ratio $\lambda_{\text {opt }}$ corresponding to the maximum power coefficient of wind turbine $\mathrm{C}_{\text {pmax }}$ for any pitch angle $\beta$. The $\beta=0$ without considering wind turbine status at extreme wind speed.

The output torque of wind turbine is [4]:

$$
T_{m}=\frac{P_{m}}{W_{w t}}
$$

The relation between $C_{p}, \beta$ and $\lambda$ is shown in Fig .3.

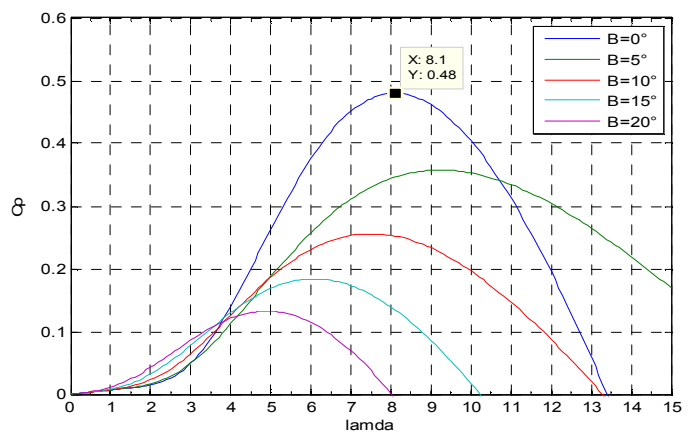

Figure 3. Aerodynamic power coefficient variation $C_{p}$ against tip speed ratio $\lambda$ and pitch angle $\beta$.

The maximum value of $C_{p}\left(C_{p \max }=0.48\right)$ is achieved for $\beta=0$ degree and for $\lambda_{\text {opt }}=8.1$.

To extract the maximum power generated, we must fix the advance report $\lambda_{\text {opt }}$ is the maximum power cient $C_{\text {pmax }}$.

\subsubsection{Generator Model}

In real wind power market, three types of wind power system for large WTs exist. The first type is fixed-speed wind power (SCIG), directly connected to the grid. The second one is a variable speed wind system using a DFIG or SCIG. The third type is also a variable speed WT, PMSG [16].
The IG space vector model is generally composed of three sets of equations: voltage equations, flux linkage equations, and motion equation. The voltage equations for the stator and rotor of the generator in the arbitrary reference frame are given by [17]:

$$
\begin{aligned}
& \left\{\begin{array}{l}
v_{d s}=\bar{R}_{s} \bar{i}_{d s}-\bar{\varphi}_{q s}+\frac{1}{w_{s}} \frac{d}{d t} \bar{\varphi}_{d s} \\
v_{q s}=\bar{R}_{s} \bar{i}_{q s}+\bar{\varphi}_{d s}+\frac{1}{w_{s}} \frac{d}{d t} \bar{\varphi}_{q s}
\end{array}\right. \\
& \left\{\begin{array}{l}
v_{d r}=\bar{R}_{r} \bar{i}_{d r}-s \cdot \bar{\varphi}_{q r}+\frac{1}{w_{s}} \frac{d}{d t} \bar{\varphi}_{d r}=0 \\
v_{q r}=\bar{R}_{r} \bar{i}_{q r}+s \cdot \bar{\varphi}_{d r}+\frac{1}{w_{s}} \frac{d}{d t} \bar{\varphi}_{q r}=0
\end{array}\right.
\end{aligned}
$$

The electrical torque is given by this equation after several converted steps:

$$
\begin{aligned}
& T_{e}=\bar{L}_{m}\left(\bar{i}_{d r} \cdot \bar{i}_{q s}+\bar{i}_{q r} \cdot \bar{i}_{d s}\right) \\
& \frac{d w_{r}}{d t}=\frac{T_{m}-T_{e}}{J}
\end{aligned}
$$

The power flow studies in the IG are represented in Fig .4 [14].

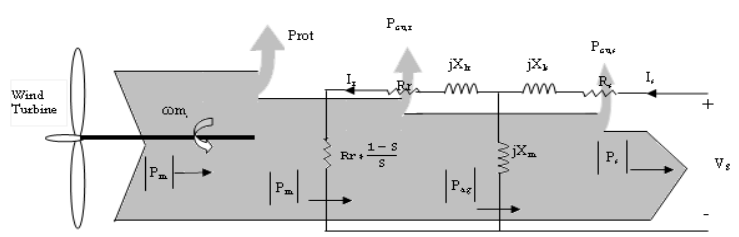

Figure 4. Power flow and losses in an IG.

\section{Statcom}

A STATCOM is a controlled reactive-power source. It provides the desired reactive-power generation and absorption entirely by means of electronic processing of the voltage and current waveforms in a voltage source converter (VSC). This function is identical to the synchronous condenser with rotating mass, but its response time is extremely faster than of the synchronous condenser. This rapidity is very effective to increase transient stability, to enhance voltage support, and to damp low frequency oscillation for the transmission system [5].

The schematic representation of the STATCOM and its equivalent circuit are shown in Fig 5.

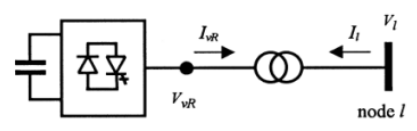

Figure 5. STATCOM, VSC connected to the AC network via a shunt transformer. 
The STATCOM has the ability to either generate or absorb reactive power by suitable control of the inverted voltage $\left|V_{v R}\right|<\theta_{v R}$, with respect to the AC voltage on the high-voltage side of the STATCOM transformer, say node $1,\left|v_{l}\right|<\theta_{l}$.

In an ideal STATCOM, with no active power loss involved, the following reactive power equation yields useful insight into how the reactive power exchange with the $\mathrm{AC}$ system is achieved.

$$
\begin{aligned}
& Q_{v R}=\frac{\left|v_{l}\right|^{2}}{x_{v R}}-\frac{\left|v_{l}\right|\left|v_{v R}\right|}{x_{v R}} \cos \left(\theta_{l}-\theta_{v R}\right) \\
& =\frac{\left|v_{l}\right|^{2}-\left|v_{l}\right|\left|v_{v R}\right|}{x_{v R}}
\end{aligned}
$$

Where $\theta_{\mathrm{l}}=\theta_{\mathrm{vR}}$ for the case of a lossless STATCOM; If $\left|v_{l}\right|>\left|v_{v R}\right|$ then $Q_{v R}$ becomes positive and the STATCOM absorbs reactive power. On the other hand, $Q_{V R}$ becomes negative if $\left|\mathrm{v}_{\mathrm{l}}\right|<\left|\mathrm{v}_{\mathrm{vR}}\right|$ and the STATCOM generates reactive power.

In power flow studies the STATCOM may be represented in the same way as a synchronous condenser, which in most cases is the model of a synchronous generator with zero active power generation. It is adjusts the voltage source magnitude and phase angle using Newton's algorithm to satisfy a specified voltage magnitude at the point of connection with the AC network as presents at the Fig. 5 .

$$
v_{v R}=\left|v_{v R}\right|\left(\cos \theta_{v R}+j * \sin \theta_{v R}\right)
$$

It should be pointed out that maximum and minimum limits will exist for $\left|v_{\mathrm{vR}}\right|$ which are a function of the STATCOM. Capacitor rating. On the other hand, $\theta_{\mathrm{vR}}$ can take any value between 0 and $2 \pi$ radians but in practice it will keep close to $\theta_{1}[18]$.

STATCOM is capable of providing capacitive reactive power for network with a very low voltage level near0.15pu. It also is able to generate its maximum capacitive power independent of network voltage. This capability will be very beneficial in time of a fault or voltage collapse or other restrictive phenomena, as presents at the Fig $6[10]$.

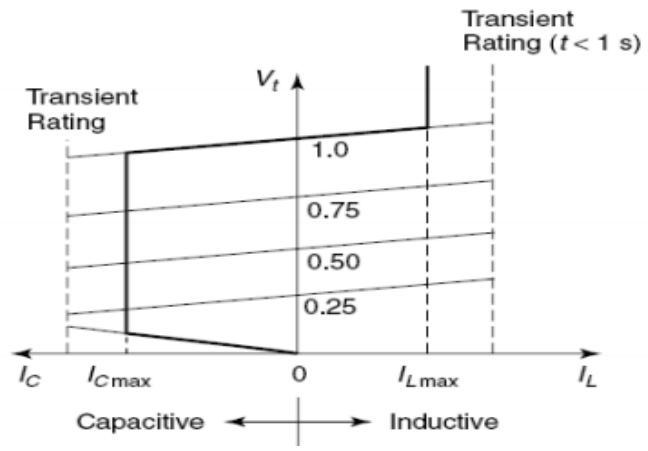

Figure 6. Voltage current characteristic of STATCOM.

\section{Simulation Results}

The proposed test system has a wind farm connected to a network of 6 bus bars; the type of generators is an IG. Under normal operating conditions, the wind farm provide $9 \mathrm{MW}$, the bank condenser used for offer a reactive power to the IG, as presents at the following Fig .7.

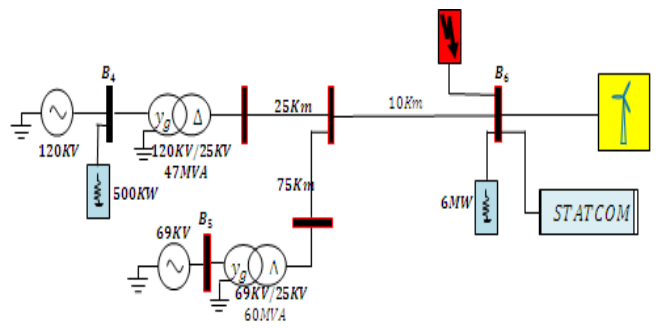

Figure 7. Test system.

The first objective of this paper is to evaluate the specific needs of the system to restore to its initial state as quickly as possible after fault clearing.

\subsection{Without STATCOM}

The effect of a three phase short circuit fault at the load bus is studied. The ground fault is initiated at $t=15 \mathrm{~s}$ and cleared at $\mathrm{t}=16 \mathrm{~s}$. The system is studied under different conditions at the load bus as chosen below.

Fig 8 and Fig 9 shows the active and reactive power at the load bus, we can see the active power curve reached $8.7 \mathrm{MW}$ in transient state operation and return near to zero in the steady state mode even with the presence of the fault, however we find a peak in the reactive power curve at the time of the application fault and stabilized at -1 Mvar.

Fig 10 and 11 shows the active and reactive power of each wind turbine.

It is clear according to these results that the active and reactive power of wind farm are disconnected before the appearance of fault, because the insufficient of the excitation condenser of generator, and the wind farm protection systems, however the reactive power gives a negative value because the presence of the condenser.

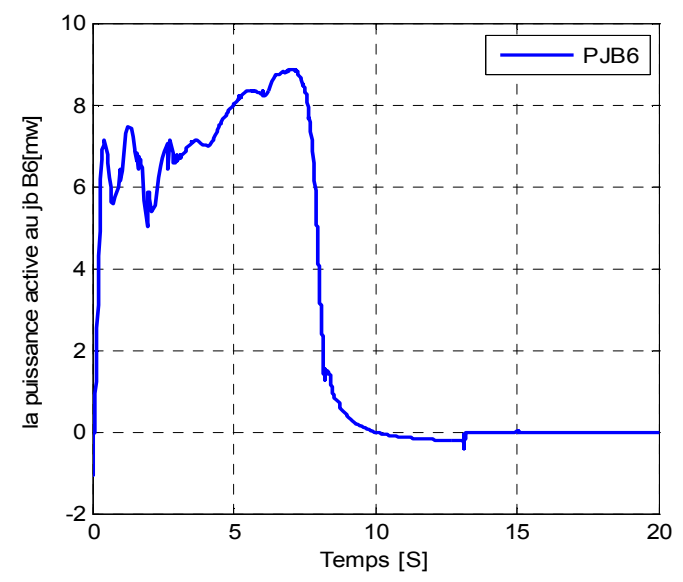

Figure 8. Active power at bus 6. 


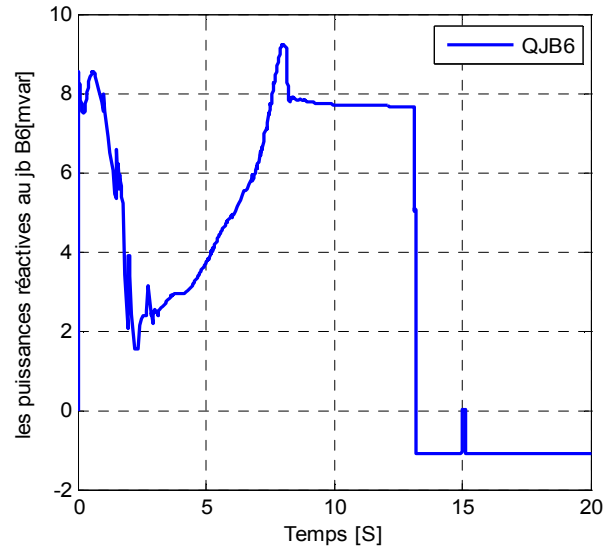

Figure 9. Reactive power at bus 6 .

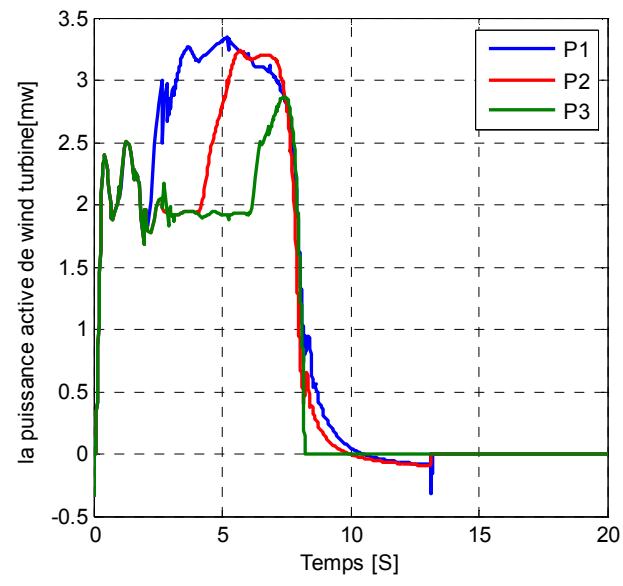

Figure 10. Active power of wind farm.

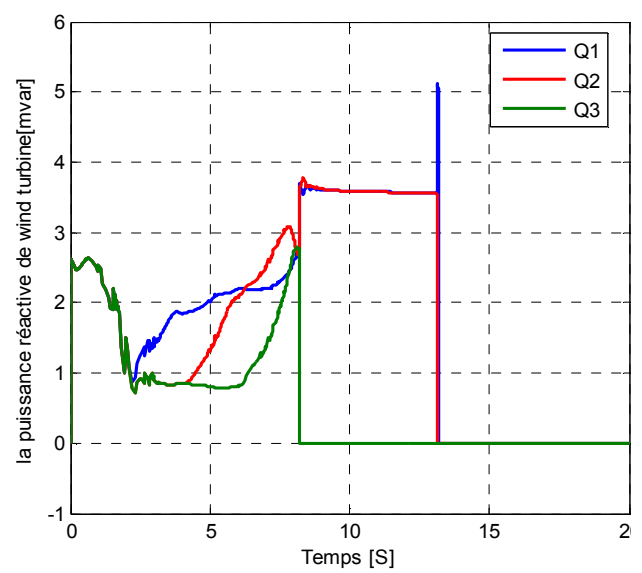

Figure 11. Reactive power of wind farm.

\subsection{With STATACOM}

According to the previous simulation results, we added the STATCOM at bus 6 for view the STATCOM effects.

Fig 12 and 13 shows the active and reactive power at the load bus, we can note that in the both curves the two powers also stabilized faster with less oscillation compared with the preceding case in the transient state and even after the fault, however fig 14 and 15 shows the active and reactive power for each wind turbine.
According to the simulation results, the curves presented above shows the importance of the compensation when the wind farm recovers its operation after the fault and takes its stability with some oscillation by the intervention of STATCOM at bus bar 6 .

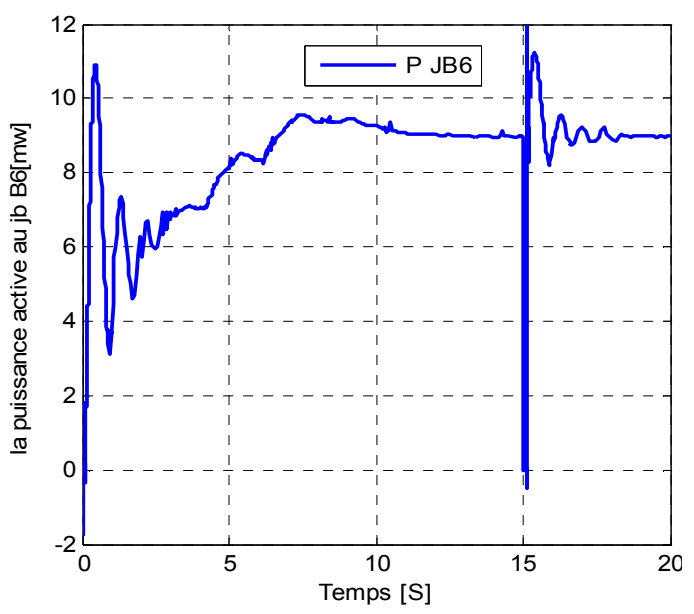

Figure 12. Active power at bus 6.

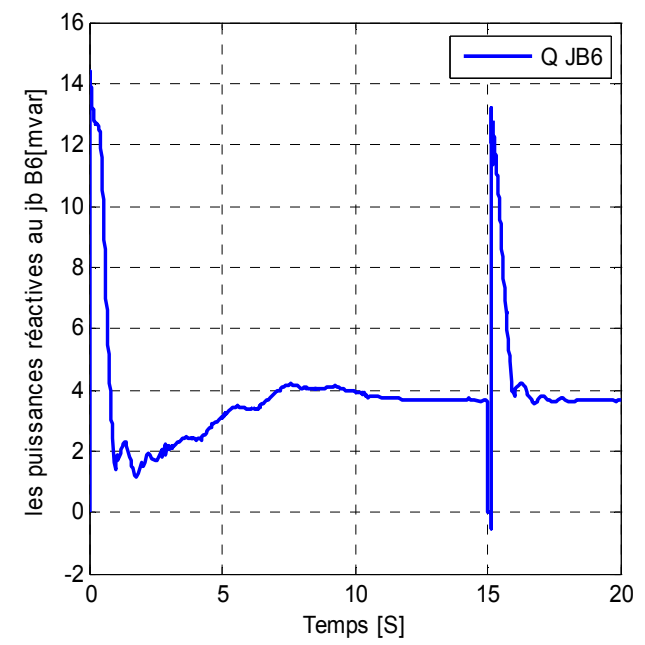

Figure 12. Active power at bus 6.

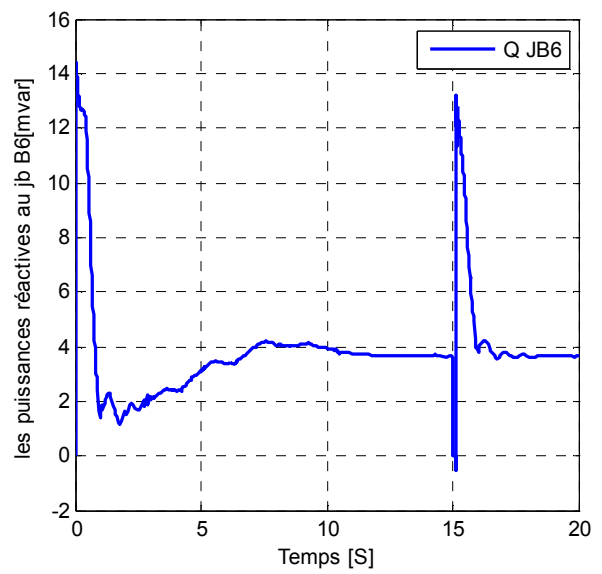

Figure 13. Reactive power at bus 6. 


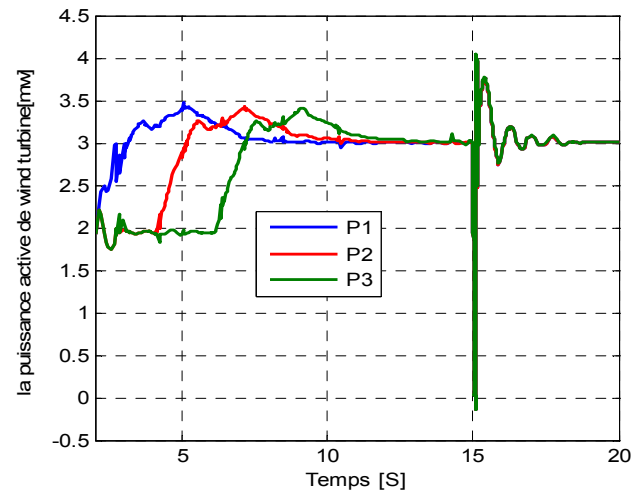

Figure 14. Active power of Wind Farm.

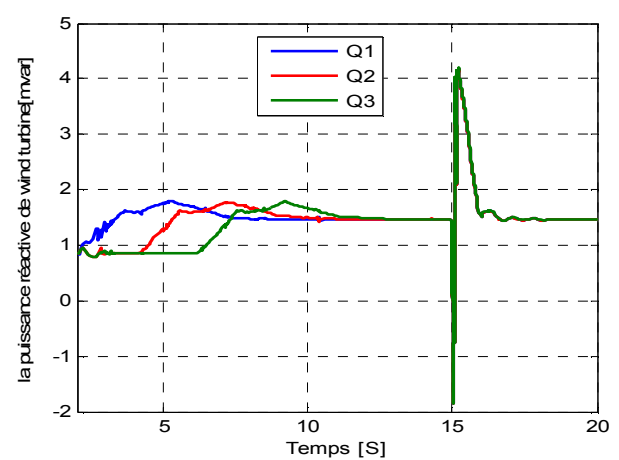

Figure 15. Reactive power of Wind farm.

\subsection{Transient Stability}

In this section, the following evaluation index is used to show the impact of grid-connected wind farms of IG type on the transient stability test system.

Critical clearance time (CCT) of faults is generally considered as the best measurement of severity of a contingency and thus widely used for ranking contingencies in accordance with their severity; in addition CCT is defined as the longest allowed fault clearance time without losing stability [4]. In our studies, the CCT is employed as a transient stability index to evaluate the test system; we use a different value of reactive power injecting by a STATCOM for controller the CCT.

Fig 16 shows CCT for several values of STATCOM, we illustrate that the relation between the reactive power injecting by a STATCOM and the CCT is nearly a linear.

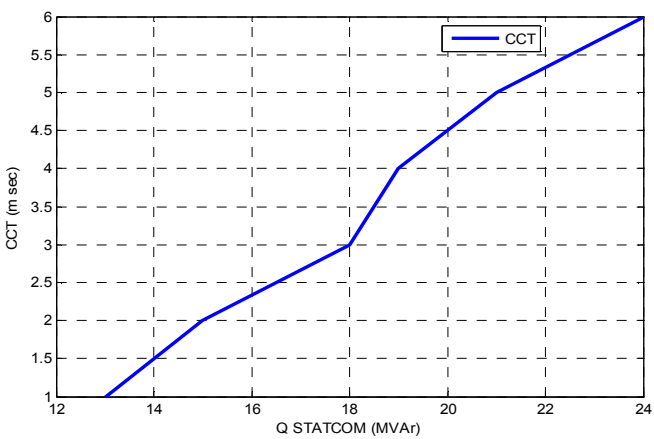

Figure 16. Critical time for several values of STATCOM.

\section{Conclusions}

The increasing penetration of renewable energy sources in the grid, high demands, caused destabilized the electrical network, so the researchers must be finding and master a new techniques for produced more power, better quality and higher reliability at lower cost. In first section a global description of system was presented, for each its component a brief presentation are given, modeled and simulated.

In the second section, the dynamics of the gridconnected wind farm is compared with and without the presence of STATCOM under fault, our test network contain three wind farm each wind farm has two equal wind turbine, according to the simulation results, it clearly illustrates the need of STATCOM improvement when the wind farm recovers its operation after the fault and takes its stability and do not leave the wind farm disconnect in the insufficient of the excitation condenser case. In the last section, a several successive simulation are executed for understand the relation between the STATCOM dimension and the CCT.

\section{References}

[1] AL. Olimpo, J. Nick, E. Janaka, C. Phill and H Mike, "Wind Energy Generation Modelling and Control," John Wiley \& Sons, Ltd 2009.

[2] H. Mellah and K. E. Hemsas, "Design and Analysis of an External-Rotor Internal-Stator Doubly Fed Induction Generator for Small Wind Turbine Application by Fem," International Journal of Renewable and Sustainable Energy. vol. 2, no. 1, pp. 1-11, 2013.

[3] A. Petersson, "Analysis Modeling and Control of DoublyFed Induction Generators for Wind Turbines," $\mathrm{PhD}$ thesis, Chalmers university of technology, GOteborg, Sweden 2005.

[4] B .BOUHADOUZA, "Amélioration de la Stabilité Transitoire des Fermes Eoliennes par l'utilisation des STATCOM," magister theses of Setif university, Algeria, 2011.

[5] A. Pahade and N. Saxena, "Transient stability improvement by using shunt FACT device (STATCOM) with Reference Voltage Compensation (RVC) control scheme," International Journal of Electrical, Electronics and Computer Engineering, vol. 2, pp.7-12, 2013.

[6] S. Chauhan, V. Chopra, S. Singh, "Transient Stability Improvement of Two Machine System using Fuzzy Controlled STATCOM," International Journal of Innovative Technology and Exploring Engineering, vol. 2,pp. 52-56, March 2013.

[7] V. K. Chandrakar, A. G. Kothari, "Comparison of RBFN based STATCOM, SSSC and UPFC Controllers for Transient Stability improvement," Power Systems Conference and Exposition, PSCE '06, pp. 784 - 791, IEEE PES 2006.

[8] M. Mohammad Hussaini, R. Anita, "The Study of Dynamic Performance of Wind Farms with the Application Trends in Engineering," International Journal of Recent Trends in Engineering, vol. 2, pp. 158-160, 2009

[9] P. Kumkratug, "The Effect of STATCOM on Inter-Area 
Power System Stability Improvement," IEEE computer society conference, Second UKSIM European Symposium on Computer Modeling and Simulation, pp. 359-363, 2008.

[10] X. Zhang, C. Rehtanz and B. Pal, "Flexible AC Transmission Systems: Modelling and Control," Publisher: Springer, 2006.

[11] H. Li, Z. Chen, "Overview of different wind generator systems and their comparisons," IET, Renewable Power Generation, vol. 2, pp. 123-138, 2008.

[12] A. Olimpo, J. Nick, E. Janaka, C. Phill and H Mike, "Wind Energy Generation Modelling and Control, John Wiley \& Sons, Ltd 2009.

[13] J.G. Slootweg, S. de Haan, H. Polinder, W. L. Kling, "Modeling wind turbines in power system dynamics simulations," Power Engineering Society Summer Meeting, Vol. 1, pp. 22 -26, IEEE, 2001.

[14] M. Huong Nguyen, T. K. Saha, "Dynamic simulation for wind farm in a large power system," Power Engineering Conference, AUPEC '08. Australasian Universities, pp. 1 -6, IEEE, 2008.
[15] L. Shenghu , L. Zhengkai , H. Xinjie , J. Shusen, "Dynamic equivalence to induction generators and wind turbines for power system stability analysis," 2nd IEEE International Symposium on Power Electronics for Distributed Generation Systems (PEDG), pp. 887 - 892, IEEE 2010.

[16] H. Mellah, K. E. Hemsas, "Simulations Analysis with Comparative Study of a PMSG Performances for Small WT Application by FEM," International Journal of Energy Engineering, vol.3, no 2, pp. 55-64, 2013.

[17] B. wu, Y. Lang, N. Zargari, S. Kouro, "power conversion and control of wind energy systems," IEEE press, wiley, Canada 2010

[18] E.Acha, V.G.Agelidis, O.Anaya-lara, T.J.E.Miller, "power Electronic Control in Electrical Systems", Newnes. A division of reed educational and professional publishing ltd, 2002.

[19] M. A. Kamarposhti, M. Alinezhad, "Comparison of SVC and STATCOM in Static Voltage Stability Margin Enhancement", International Journal of Electrical Power and Energy Systems Engineering, 2010. 